\title{
The Blunted Plasma Cortisol Response to Apomorphine and Its Relationship to Treatment Response in Patients with Schizophrenia
}

Herbert Y. Meltzer, M.D., Myung A. Lee, M.D., and Karuna Jayathilake, M.S.

The adrenocorticotropic hormone (ACTH) and cortisol responses to apomorphine (APO), a direct acting dopamine (DA) agonist, have been reported to be significantly blunted in neuroleptic-free patients with schizophrenia (SCH). This study primarily examined the cortisol, but also the prolactin (PRL) and growth hormone (GH), response to APO in patients with SCH compared to normal controls, as well as the relationship between endocrine measures and response to antipsychotic drug treatment. APO, $0.01 \mathrm{mg} / \mathrm{kg}$, or placebo was administered to 51-98 patients with SCH and 15-25 normal controls. Psychopathology was assessed at the baseline and six weeks after drug treatment. The plasma cortisol response to APO was markedly blunted in patients with $\mathrm{SCH}$ compared to normal controls. Patients who responded to six weeks of treatment with antipsychotic drugs had a higher cortisol response to APO compared to non-responders. The plasma $G H$, but not PRL, response to APO was blunted in male patients with $S C H$. Neither plasma GH nor PRL responses to APO were related to treatment response at six weeks. These results provide further evidence of dopaminergic dysfunction in SCH. Furthermore, the APO-stimulated cortisol response may be predictive of subsequent clinical response to antipsychotic drug treatment.

[Neuropsychopharmacology 24:278-290, 2001] (C) 2001 American College of Neuropsychopharmacology. Published by Elsevier Science Inc.
KEY WORDS: Cortisol; Apomorphine; Antipsychotic drug; Schizophrenia

Apomorphine (APO) is a direct acting dopamine (DA) agonist with similar potency at $\mathrm{D}_{2}$ and $\mathrm{D}_{3}$ receptors (Sokoloff et al. 1990). It is also a weak $\mathrm{D}_{4}$ agonist (Seeman and Van Tol 1990; Mansbach et al. 1998), and a partial $D_{1}$ receptor agonist (Creese 1987). Numerous studies have examined the growth hormone $(\mathrm{GH})$ and prolactin (PRL) response to APO in patients with

From the Department of Psychiatry, Vanderbilt University Medical Center, Nashville, TN 37212

Address correspondence to: Herbert Y. Meltzer, M.D., Department of Psychiatry, Vanderbilt University, $160123^{\text {rd }}$ Avenue South, Suite 306, Nashville, TN 37212, Tel.: 615-327-7049, Fax: 315-3277093, e-mail: herbert.meltzer@mcmail.vanderbilt.edu

Received April 6, 2000; revised August 8, 2000; accepted August 25,2000 schizophrenia $(\mathrm{SCH})$ in order to study the role of DA in the etiology of schizophrenia and the mechanism of action of antipsychotic drugs (Meltzer et al. 1984; Zemlan et al. 1986; Tamminga et al. 1977; Muller-Spahn et al. 1998; Brown et al. 1988; Lieberman and Koreen 1993; Ettigi et al. 1976; Ferrier et al. 1984). In addition to effects on GH and PRL, APO also stimulates adrenocorticotropic hormone (ACTH) and cortisol in man (Jezova and Vigas 1988; Mokrani et al. 1995) and animals (Surmann and Havemann-Reinecke 1995).

In the only published study of the effect of APO on the hypothalamic-pituitary adrenal (HPA) axis in $\mathrm{SCH}$, Mokrani et al. (1995) reported blunted plasma adrenocorticotropic hormone (ACTH) and cortisol responses to APO in drug-free patients with $\mathrm{SCH}(\mathrm{N}=46)$ or schizoaffective disorder (SAD) $(\mathrm{N}=16)$, compared to both hospitalized medical controls $(\mathrm{N}=18)$ and pa- 
tients with major depression $(\mathrm{N}=50)$. Mokrani et al. (1995) also reported significant positive correlations between the GH response and the cortisol and ACTH responses to APO in these groups of subjects. The blunted $\mathrm{HPA}$ axis responses were present in patients with $\mathrm{SCH}$, paranoid type, or schizoaffective disorder, but not in patients with $\mathrm{SCH}$, disorganized type.

Most studies report the GH response to APO in chronic $\mathrm{SCH}$ is not significantly different from that of normal controls (Tamminga et al. 1977; Meltzer et al. 1984; Muller-Spahn et al. 1998: Zemlan et al. 1986; Brown et al. 1988; Lieberman and Koreen 1993) However, a few studies found blunted GH response in patients with SCH (Ettigi et al. 1976; Ferrier et al.; 1984) while others report an enhanced response, especially in more acutely ill patients (Cleghorn et al. 1983; Zemlan et al. 1986). There is evidence that these discrepancies may relate to differences in gender and duration of illness (Meltzer et al. 1984, Ferrier et al. 1984) with diminished GH response to APO more likely in male patients with greater duration of illness.

Most studies have reported that the APO-induced PRL suppression in patients with SCH was not different from the control groups (Meltzer et al. 1984; Ettigi et al. 1976; Ferrier et al. 1984; Mokrani et al. 1995). However, Tamminga et al. (1977) reported that APO produced a lesser decrease in serum PRL levels in patients with $\mathrm{SCH}$ than normals.

Neural mechanisms mediating APO-stimulated HPA axis responses appear to differ from those of APO-induced GH or PRL responses (to be discussed in more detail subsequently). Animal studies have reported that DA agonist-stimulated HPA axis responses are mediated via $D_{1}$ and/or $D_{2}$ receptor stimulation (Borowsky and Kuhn 1992; Fuller and Snoddy 1984). In addition, ventral striatum, which is one of anatomical regions related to pathophysiology of $\mathrm{SCH}$, has been reported to be involved in the corticosterone secretion induced by the combined administration of $\mathrm{D}_{1} / \mathrm{D}_{2}$ agonists (SKF 38393/quinpirole) in rats (Ikemoto and Goeders 1998). Thus, the APO-stimulated HPA axis responses may reflect mesolimbic $D_{1}$ and/or $D_{2}$ receptor function, which makes it more ideal than the APOinduced GH or PRL response for the study of DA receptor function in $\mathrm{SCH}$.

The purpose of this study was to determine whether the plasma cortisol response to APO in unmedicated patients with $\mathrm{SCH}$ was significantly diminished compared to that of normal controls. In addition, we also examined the relationship between the APO-stimulated cortisol response, psychopathology, and response to antipsychotic drug treatment. Furthermore, we contrasted the cortisol response to APO to GH and PRL responses to APO to examine relationships between them. Data on GH and PRL responses to APO from a subgroup of patients with $\mathrm{SCH}(\mathrm{N}=40)$ and normal controls $(\mathrm{N}=16)$ have been previously reported (Meltzer et al. 1984). This study reports data on GH and PRL responses to APO in the final sample (71-98 patients) including data from previously reported subjects.

\section{METHODS}

\section{Subjects}

The effect of APO on plasma cortisol (APO-CORT) was determined in 51 patients $(42 \mathrm{M}, 9 \mathrm{~F}$; mean age $36.1 \pm 8.3$ yrs) meeting DSM-III-R (American Psychiatric Association 1987) criteria for SCH or SAD and 15 normal controls (10 M, 5 F; mean age $25.5 \pm 5.7 \mathrm{yrs})$. Diagnosis was established on the basis of the Schedule for Affective Disorders and Schizophrenia Lifetime (SADS-L) and Change (SADS-C) versions (Endicott and Spitzer 1978). A history of response to neuroleptic treatment was obtained from the patients, from medical records and significant others, in order to classify patients as neuroleptic resistant or not by the criteria of Kane et al. (1988). Twenty-one patients $(41.2 \%)$ were considered to be neuroleptic-responsive and $30(58.8 \%)$ were neuroleptic-resistant. Twenty-four patients met criteria for paranoid $\mathrm{SCH}, 20$ for undifferentiated $\mathrm{SCH}$, one for disorganized $\mathrm{SCH}$, and one for SAD. Demographic characteristics and baseline psychopathology of the patients $\mathrm{SCH}$ are presented in Table 1. GH data (APO$\mathrm{GH})$ were available for 71 patients with $\mathrm{SCH}(61 \mathrm{M}, 10$ F; mean age $34.9 \pm 7.2$ yrs). Of these, $31(43.7 \%)$ were neuroleptic-resistant $\mathrm{SCH}$. One patient could not be reliably classified. These data were compared to that from 16 normal controls (13 M, 3 F; mean age $34.6 \pm 11.8$ years). Thirty-two patients and six normal controls had both GH and cortisol data. PRL data (APO-PRL) was available from 98 patients with $\mathrm{SCH}(84 \mathrm{M}, 14 \mathrm{~F}$; mean age $35.8 \pm 7.7$ yes) and 25 controls $(19$ M, 6 F; mean age $30.4 \pm 10.5$ yes). Of those, $50(51.0 \%)$ were neurolepticresistant $\mathrm{SCH}$ and four patients who could not be reliably classified in this regard. Serum PRL and cortisol data were available from 47 patients and 8 controls.

The normal controls were interviewed using SADS-L to screen for psychiatric illness in themselves as well as first-degree relatives. All subjects were screened for any significant medical and neurological problems by history and physical examination, comprehensive blood and urine tests, and urine drug screen. CT or MRI of the head, or EEG, or both, were performed if necessary to rule out neurological abnormalities.

Patients were drug-free for at least seven days before APO challenge, either because of non-compliance prior to admission, or agreed to neuroleptic withdrawal in order to participate in this study. No patient had received a depot neuroleptic within two cycles of their prior administration schedule. Patients were closely 
Table 1. Demographic and Clinical Characteristics of Patients with Schizophrenia

\begin{tabular}{|c|c|c|c|}
\hline & $\begin{array}{l}\text { APO-CORT } \\
(\mathbf{N}=51)\end{array}$ & $\begin{array}{c}\text { APO-GH } \\
(\mathbf{N}=71)\end{array}$ & $\begin{array}{l}\text { APO-PRL } \\
(\mathbf{N}=98)\end{array}$ \\
\hline Age (yr.) & $36.6 \pm 8.4$ & $34.9 \pm 7.2$ & $35.8 \pm 7.7$ \\
\hline $\mathrm{M} / \mathrm{F}$ & $42 / 9$ & $61 / 10$ & $84 / 14$ \\
\hline Duration of illness & $15.0 \pm 7.5 \mathrm{yrs}$ & $14.0 \pm 6.6$ & $14.3 \pm 6.5$ \\
\hline BPRS $^{a}$ Total & $28.7 \pm 12.6$ & $28.8 \pm 12.3$ & $27.5 \pm 12.3$ \\
\hline Positive & $10.8 \pm 5.3$ & $11.5 \pm 5.6$ & $10.8 \pm 5.5$ \\
\hline Withdrawal-Retardation & $4.8 \pm 4.2$ & $4.4 \pm 3.5$ & $4.3 \pm 4.0$ \\
\hline Neuroleptic-resistant/-responsive $\mathrm{SCH}^{b}$ & $30 / 21$ & $31 / 39$ & $50 / 44$ \\
\hline Paranoid/Undifferentiated/other $\mathrm{SCH}^{c}$ & $24 / 20 / 6$ & $35 / 26 / 9$ & $49 / 34 / 14$ \\
\hline
\end{tabular}

monitored during the drug-free period in order to minimize any discomfort, or to detect any early signs of deterioration, which could lead to immediate medical intervention. In addition, patients were required to be free of substance abuse for three months before entering the study.

This protocol was approved by the Institutional Review Board of University Hospital of Cleveland. Written informed consent was obtained from all patients after the procedure had been fully explained before admission to the study.

Psychopathology Ratings and Antipsychotic Drug Treatment

The Brief Psychiatric Rating Scale (BPRS) (Overall and Gorham 1962) (0-6 Scales) was employed to evaluate severity of psychopathology. In addition, in some of patients (see RESULTS), the psychopathology rating was repeated after six weeks of treatment with either clozapine or a typical neuroleptic drug. The former was given to patients who were neuroleptic-resistant or intolerant patients.

\section{APO Administration}

Subjects were fasted after midnight on the night before the testing day. On the following morning, at 8 A.M., an indwelling catheter was inserted in the forearm vein of each subject. Thirty minutes after the catheter insertion, a baseline blood sample was collected into heparinized syringes followed by two additional samples at 15 -min intervals $(\mathrm{T}-30, \mathrm{~T}-15, \mathrm{~T} 0)$. Immediately following the last baseline blood collection (T0), either APO (0.01 $\mathrm{mg} / \mathrm{kg}$ ) or normal saline (placebo) was administered subcutaneously, in random order. Each subject had two days of study at least 48 hours apart. Additional blood samples were collected at 30-min intervals for a 2-hour period. The subject was kept at bed rest during the study, except to go to the toilet if necessary. The catheter studies were conducted single blindly.
The dose of APO was $0.01 \mathrm{mg} / \mathrm{kg}$. This translated to $0.82 \pm 0.13 \mathrm{mg}$ (range: $0.59-1.17 \mathrm{mg}$ ) for patients with SCH and $0.71 \pm 0.17 \mathrm{mg}$ (range: $0.48-1.08 \mathrm{mg}$ ) for normal controls in the sample for the cortisol analysis. The mean doses were very similar for the sample in the GH and PRL analyses.

\section{Hormone Assays}

Plasma GH, PRL, and cortisol concentrations were measured by standard double antibody radioimmunoassay. The kit used to measure plasma cortisol was purchased from Diagnostic Products (Los Angeles, CA). Plasma GH and PRL assays have been described elsewhere (Meltzer et al. 1984). The within and between assay coefficients for variation for the hormone studies were less than $5 \%$.

\section{Statistical Analysis}

The plasma cortisol, GH, and PRL responses to APO were determined by the area under the curve (AUC) using Simpson's Rule. Univariate analysis of covariance (ANCOVA) was used to compare the plasma cortisol, $\mathrm{GH}$, and PRL responses to APO between groups after correcting for placebo response, as well as performing analysis on protocol effect within subjects. Baseline hormone levels were covaried for APO-CORT and APOPRL responses, and gender and age were covaried for the APO-GH and APO-PRL responses, as these variables were related with hormone responses. Weight was not covaried as it was not significantly correlated with any hormone responses to APO (data not shown). In addition, data were also analyzed for the male patients only for APO-GH and APO-PRL due to small female samples in normal controls. Data from two subjects with baseline GH levels $\geq 6 \mathrm{mg} / \mathrm{ml}$ were excluded from the analysis. The least significant difference test was used for post hoc tests of significance when the 
overall F-Test was significant. Pearson correlation coefficients were used to examine the relationships between variables.

\section{RESULTS}

\section{Baseline Plasma Cortisol, GH, and PRL Levels}

Baseline plasma cortisol levels were significantly higher in patients with $\mathrm{SCH}$ compared to normal controls $[\mathrm{F}(1,64)=9.28, p=.003]$ (Table 2). The baseline plasma $\mathrm{GH}[\mathrm{F}(1,85)=0.21, \mathrm{NS}]$ and PRL $[\mathrm{F}(1,118)=0.18, \mathrm{NS}]$ levels were not significantly different between patients with SCH and normal controls (Table 2). No gender differences in baseline plasma cortisol and GH levels were found (data not shown). However, the baseline plasma PRL levels were significantly higher in females than males in both groups $[\mathrm{F}(1,118)=7.30, p=.008]$. There was no difference in baseline plasma cortisol, GH and PRL levels between subtypes of $\mathrm{SCH}$ and between neuroleptic-resistant and responsive $\mathrm{SCH}$ (data not shown).

\section{Plasma Cortisol Responses to APO}

The time course of the cortisol response to APO was similar to that reported by Mokrani et al. (1995), with the peak increase at $60 \mathrm{~min} .[\mathrm{F}(1,60)=32.80, p=.0001]$ (Figure 1). The APO-CORT response was significantly lower in the patients with $\mathrm{SCH}$ compared to normal controls $[\mathrm{F}(1,63)=6.03, p=.02]$ (Table 2; Figures 1 and 2 ). The mean cortisol response in the patients was $74.8 \%$ lower than that of the controls. Twenty-five of 51 $(49.0 \%)$ of the SCH patients compared to only $2 / 15$ $(13.3 \%)$ of the normal controls had no change or a decrease in cortisol levels after APO administration $\left(\mathrm{X}^{2}=\right.$ $6.11, p=.01)$. The plasma cortisol response following $\mathrm{APO}$ was not different between males and females in patients with $\mathrm{SCH}(\mathrm{t}=0.89, \mathrm{df}=49, \mathrm{NS})$ or normal controls $(\mathrm{t}=0.52, \mathrm{df}=13, \mathrm{NS})$. Neuroleptic-resistant $\mathrm{SCH}$ $(\mathrm{N}=30)$ (AUC:4.4 $\left.\pm 20.1 \mathrm{~cm}^{2}\right)$ showed significantly lower APO-CORT responses compared to normal controls (AUC:28.2 $\left.\pm 27.4 \mathrm{~cm}^{2}\right)[\mathrm{F}(2,62)=3.21, p=.05]$; there was a trend for neuroleptic-responsive $\mathrm{SCH}(\mathrm{N}=$ 21)(AUC: $8.5 \pm 22.7 \mathrm{~cm}^{2}$ )to also have lower cortisol responses compared to normal controls $(p=.07)$; the two types of patients with $\mathrm{SCH}$ were not significantly different. APO-CORT responses in paranoid and undifferentiated types of $\mathrm{SCH}$ did not differ from normal controls $[\mathrm{F}(2,51)=2.39, p=.1]$; no difference in the APO-CORT response between these two subtypes of $\mathrm{SCH}$ was noted. The cortisol response to APO in the patients with $\mathrm{SCH}$ was significantly negatively correlated with baseline plasma cortisol levels $(\mathrm{r}=-0.35, \mathrm{~N}=51, p=.01)$; nonsignificant, but in the same direction was present in the normal controls $(\mathrm{r}=-0.39, \mathrm{~N}=15, p=.1)$. However, there was no significant difference in baseline plasma cortisol levels between those patients with positive cortisol responses to APO $(11.1 \pm 4.2 \mu \mathrm{g} / \mathrm{dl})$ vs. those without $(13.2 \pm 5.3 \mu \mathrm{g} / \mathrm{dl} ; \mathrm{t}=1.58, p=.12)$.

The effect of current smoking status on the APOCORT response was examined. Smoking status did not influence the APO-CORT response $[\mathrm{F}(2,22)=0.69, \mathrm{NS}]$. Similarly, both group of subjects with or without history of substance abuse had significantly lower APOCORT responses compared to normal controls (data not presented). There was no significant difference in the APO-CORT response between patients with and without history of substance abuse $(p=.4)$.

Both patients and normal controls tolerated APO without significant side effects except for occasional mild nausea. There was no difference in the APOCORT response in subjects with and without nausea (data not shown). No significant behavioral effect was observed after APO administration in either group.

\section{Plasma GH and PRL Responses to APO}

The GH response following APO were significantly lower in all females compared to males $[\mathrm{F}(1,82)=3.79, p$ $=.05]$. Due to the small number of females in normal controls $(\mathrm{N}=3)$ and the gender effect on APO-GH responses, $\mathrm{GH}$ responses were further examined in the male subjects only. The GH response to APO was significantly decreased in male patients with $\mathrm{SCH}$ compared to

Table 2. Comparison of the APO-Stimulated Plasma Cortisol, GH and PRL Responses, and Baseline Plasma Cortisol, GH and PRL Levels Between Patients with Schizophrenia and Normal Controls.

\begin{tabular}{lcccc}
\hline & Normal Controls (N) & Schizophrenia (N) & F (df) & p \\
\hline Baseline cortisol (ug/dl) & $8.1 \pm 2.8(15)$ & $12.1 \pm 4.8(51)$ & $9.28(1,64)$ & 0.003 \\
Baseline GH (ng/ml) & $0.77 \pm 0.56(16)$ & $0.87 \pm 0.78(71)$ & $0.21(1,85)$ & NS \\
Baseline PRL (ng/ml) & $5.72 \pm 2.70(25)$ & $6.85 \pm 4.71(98)$ & $0.18(1,118)$ & NS \\
APO-CORT $\left(\mathrm{cm}^{2}\right)$ & $28.2 \pm 27.4(15)$ & $6.1 \pm 21.0(51)$ & $6.03(1,63)$ & 0.02 \\
APO-GH $\left(\mathrm{cm}^{2}\right)(m a l e ~ o n l y)$ & $35.2 \pm 25.5(13)$ & $15.3 \pm 23.8(61)$ & $6.24(1,71)$ & 0.01 \\
APO-PRL $\left(\mathrm{cm}^{2}\right)($ male only) & $-4.0 \pm 9.1(19)$ & $-3.4 \pm 10.7(84)$ & $1.35(1,99)$ & NS \\
\hline
\end{tabular}

Mean \pm SD

*Placebo corrected response (AUC). 

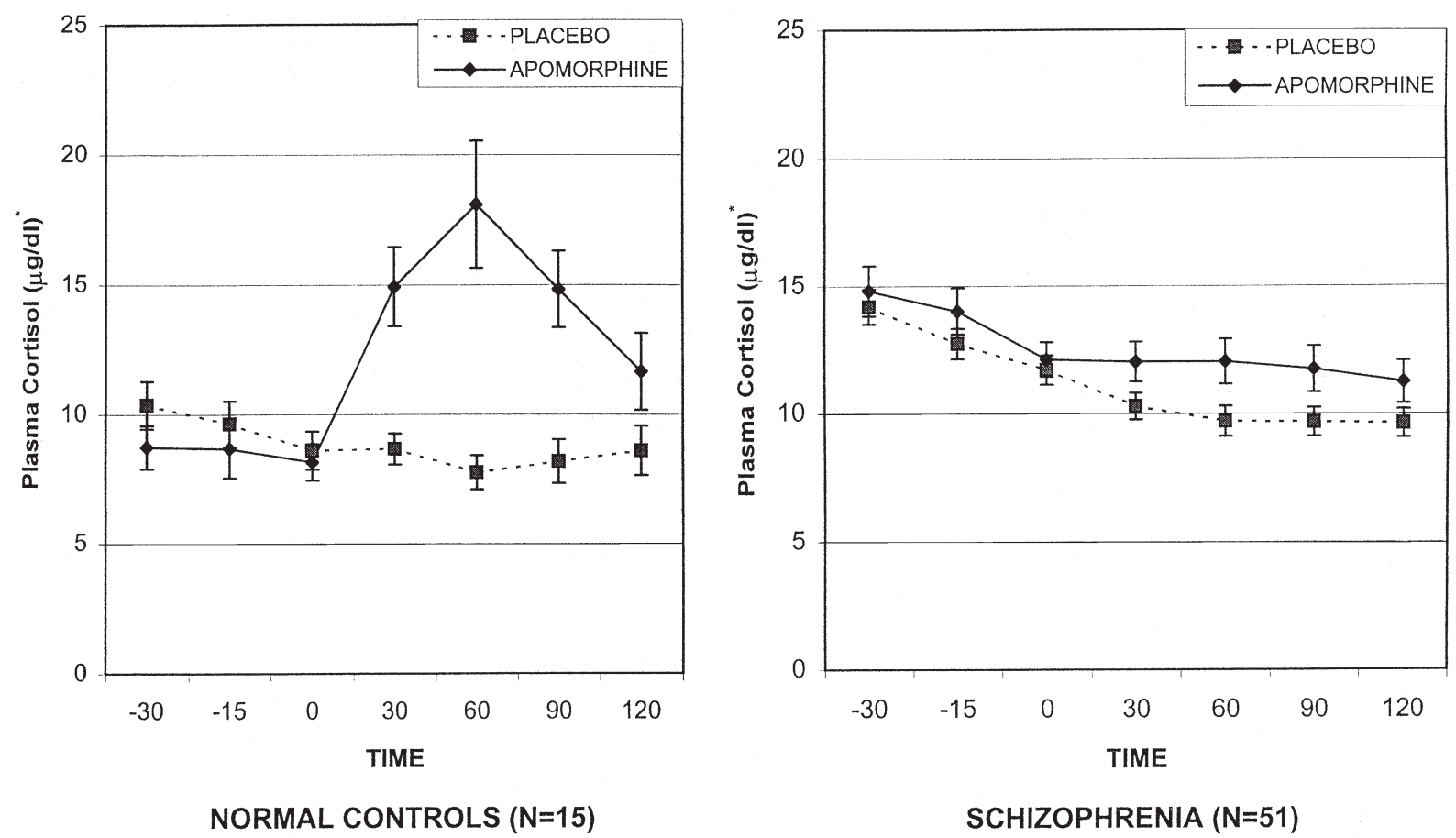

Figure 1. Plasma cortisol responses to apomorphine in patients with schizophrenia and normal controls (time course). Protocol effect: $\mathrm{F}(1,60)=32.80, p=.0001$; Protocol X Group: $\mathrm{F}(1,60)=9.20, p=.004 .{ }^{*}$ Mean \pm SE.

male normal controls $[\mathrm{F}(1,71)=6.24, p=.01]$ (Table 2, Fig. 3). The GH response in $\mathrm{SCH}$ was decreased by $56.5 \%$ compared to the controls. The blunted GH responses to APO was present in both neuroleptic-responsive and resistant male SCH patients $[\mathrm{F}(2,69)=3.19, p=.05]$ and the paranoid subtype of $\mathrm{SCH}[\mathrm{F}(2,64)=4.51, p=.05]$, but not in undifferentiated $\mathrm{SCH}(p=.1)$. The baseline $\mathrm{GH}$ levels were not significantly correlated with the GH responses to APO in either the patients with $\mathrm{SCH}(\mathrm{r}=$ -0.12 , NS) or normal controls ( $r=0.24, \mathrm{NS})$.

The PRL response following APO was not significantly different between groups $[\mathrm{F}(1,118)=2.74, p=$ .10]. However, there was a trend for a gender by proto$\operatorname{col}[\mathrm{F}(1,118)=3.02, p=.08]$ and gender $\mathrm{X}$ group $\mathrm{X}$ protocol $[\mathrm{F}(1,118)=3.03, p=.08]$ interactions. These were due to higher PRL suppression by APO in male than in female, and stimulation of PRL release by APO in female controls instead of suppression, respectively. Due to too few female controls $(\mathrm{N}=6)$ to compare with the female patients, the APO-PRL responses was examined further in the males only. The PRL response to APO was not significantly different in male patients with $\mathrm{SCH}$ compared to male normal controls $[\mathrm{F}(1,99)=1.35$, $p=.25]$. In addition, there was no significant difference between subtypes of $\mathrm{SCH}$, and between neurolepticresponsive and resistant $\mathrm{SCH}$ (data not shown). The baseline plasma PRL levels were significantly negatively correlated with APO-PRL responses in both patients with $\mathrm{SCH}(\mathrm{r}=-0.57, \mathrm{~N}=98, p=.0001)$ and normal controls $(\mathrm{r}=-0.45, \mathrm{~N}=25, p=.02)$.

\section{The Relationship between APO-stimulated Plasma Cortisol, GH, and PRL Responses}

The APO-CORT and APO-GH responses were significantly positively correlated in patients $(\mathrm{r}=0.54, \mathrm{~N}=$ $32, p=.001)$ and normal controls $(\mathrm{r}=0.87, \mathrm{~N}=6, p=$ $.02)$. The APO-CORT and APO-PRL responses were significantly positively correlated in patients $(\mathrm{r}=0.50, \mathrm{~N}=$ $47, p=.03)$, but not in normal controls $(\mathrm{r}=0.50, \mathrm{~N}=8$, $p=.2)$. The APO-PR1 and APO-GH responses were significantly negatively correlated in normal controls $(\mathrm{r}=$ $-0.56, p=.05)$, but positively in the patients $(\mathrm{r}=0.33$, $\mathrm{N}=68, p=.005$ ). The APO-GH response was not significantly different between the patients with no change or a decrease in cortisol levels and the patients with an increase in cortisol following APO in the total sample $[\mathrm{F}(1,26)=1.95, p=.17]$ as well as in males only $[\mathrm{F}(1,22)=$ $1.73, p=.2]$. The APO-PRL response showed a trend for a greater suppression in male patients with no change or a decrease in cortisol levels than in patients with an increase in cortisol following $\mathrm{APO}[\mathrm{F}(1,35)=3.43, p=$ .07], but there was no difference in the total sample $[\mathrm{F}(1,42)=2.83, p=.1]$.

\section{The Relationship between the Plasma Cortisol, GH, and PRL Responses to APO and Psychopathology, the Drug Washout Period, and the Duration of Illness}

The plasma cortisol response to APO was not significantly correlated with BPRS Total scores $(\mathrm{r}=-0.04$, 


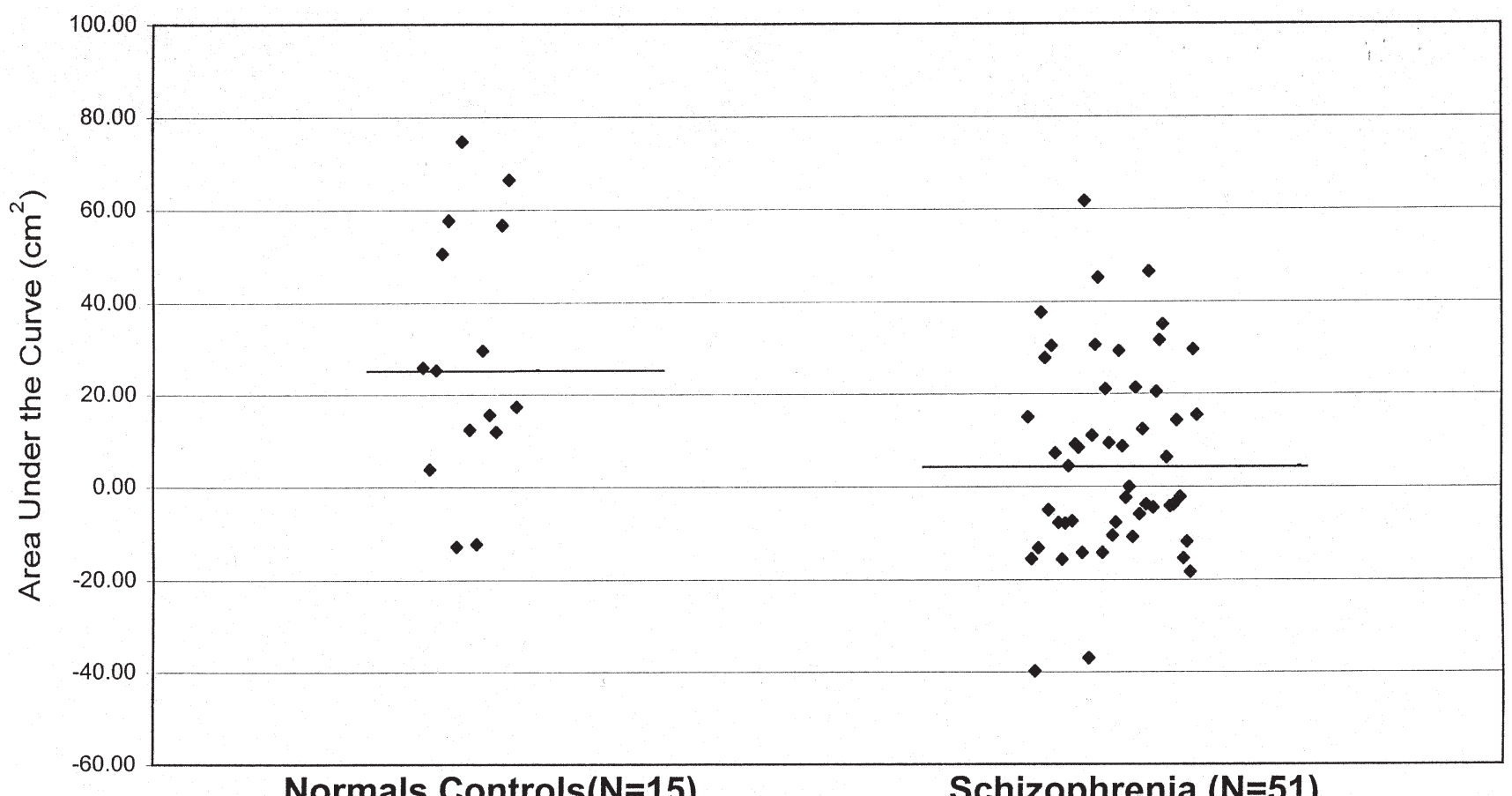

Figure 2. Plasma cortisol responses to apomorphine in patients with schizophrenia and normal controls (a scatter plot using placebo corrected responses). Normal controls vs. schizophrenia: $\mathrm{F}(1,63)=6.03, p=.02$.

NS), BPRS Positive ( $\mathrm{r}=-0.04$, NS) and WithdrawalRetardation $(r=0.13$, NS) subscales, the drug washout period $(r=-0.05, N S)$, or the duration of illness $(r=$ -0.16 , NS). The subjects who did not have an increase in plasma cortisol levels after APO did not differ in psychopathology from those who did have an increase (data not shown). They also did not differ in age, age at onset, duration of illness or number of previous hospitalizations (data not shown).

Plasma GH responses to APO were not significantly correlated with BPRS Total ( $\mathrm{r}=0.21, p=.1$ ), BPRS Positive $(r=0.16, N S)$ or Withdrawal-Retardation $(r=$ $0.11, \mathrm{NS})$, or the drug washout period $(\mathrm{r}=-0.17$, NS). However, there was a trend for a negative correlation with duration of illness $(\mathrm{r}=-0.21, p=.08)$.

Plasma PRL responses to APO were not significantly correlated with BPRS Total ( $\mathrm{r}=0.18, p=.1)$, BPRS Positive $(\mathrm{r}=0.22, p=.1)$ or Withdrawal-Retardation $(\mathrm{r}=$ $0.05, \mathrm{NS})$, duration of illness $(\mathrm{r}=-0.07, \mathrm{NS})$ or duration of drug washout period $(r=0.03, N S)$.

\section{The Relationship between the Cortisol, GH, and PRL Responses to APO and Response to Drug Treatment at Six Weeks}

Thirty-five patients (26 neuroleptic-resistant, 9 neuroleptic-responsive) with pretreatment APO-CORT data, 42 patients with APO-GH data, and 40 patients with APO-PRL data had BPRS assessments at baseline and after six weeks of drug treatment. Patients were di- vided into treatment responders and non-responders based on $\geq 20 \%$ improvement of BPRS Total scores compared to baseline. The APO-CORT response was significantly higher in responders $(\mathrm{N}=13$, AUC:22.0 \pm $\left.20.3 \mathrm{~cm}^{2}\right)$ than non-responders $(\mathrm{N}=22$, AUC:0.6 \pm 15.6 $\left.\mathrm{cm}^{2}\right)(\mathrm{t}=-3.51, \mathrm{df}=33, p=.001)$. The APO-CORT response was also examined separately in the 16 patients treated with clozapine. Clozapine responders $(\mathrm{N}=7$, AUC:18.7 $\pm 19.9 \mathrm{~cm}^{2}$ ) had significantly higher cortisol responses compared to non-responders $(\mathrm{N}=9$, AUC: $\left.-1.5 \pm 16.9 \mathrm{~cm}^{2}\right)(\mathrm{t}=-2.20, \mathrm{df}=14, p=.04)$. On the other hand, the APO-GH response was not significantly different between responders $(\mathrm{N}=15)$ and nonresponders $(\mathrm{N}=27)$ in the total sample $(\mathrm{t}=0.20, \mathrm{df}=$ $40, \mathrm{NS})$, in male patients only (14/35 responders) $(\mathrm{t}=$ $0.66, \mathrm{df}=33, \mathrm{NS})$, or in male clozapine-treated patients $(4 / 10$ responders) $(t=1.11, \mathrm{df}=8.0, \mathrm{NS})$. Similarly, the APO-PRL response was not significantly different between responders $(\mathrm{N}=16)$ and non-responders $(\mathrm{N}=$ 24) in the total sample $(\mathrm{t}=-1.63, \mathrm{df}=38, p=.1)$, in male patients $(13 / 31$ responders) $(t=-1.09 . \mathrm{df}=29$, $\mathrm{NS})$ or in male patients treated with clozapine $(7 / 16$ responders) $(\mathrm{t}=0.70, \mathrm{df}=14, \mathrm{NS})$.

\section{DISCUSSION}

The major findings of this study are 1) the plasma cortisol response to APO was blunted in male and female patients with $\mathrm{SCH}$ compared to normal controls; 2) the 
plasma GH response to APO was blunted in the male $\mathrm{SCH}$ compared to male normal controls; 3) poor responders to six weeks of antipsychotic drug treatment had significantly lower APO-CORT responses compared to better responders; 4) the baseline cortisol level was significantly higher in patients with $\mathrm{SCH}$ compared to normal controls. In addition, the GH and PRL responses to APO were significantly positively correlated with the APO-CORT response in patients with $\mathrm{SCH}$.

\section{The Hormone Responses to APO}

The extent of blunting of the plasma cortisol responses to APO in patients with $\mathrm{SCH}$ compared to normal controls observed here was similar to that reported by Mokrani et al. (1995). These authors also reported blunting of the ACTH response to APO in patients with $\mathrm{SCH}$. This suggests that the diminished cortisol response to API in patients with $\mathrm{SCH}$ is centrally mediated. Further evidence in support of this will be presented subsequently. No evidence for a DA-mediated effect to increase cortisol secretion from bovine adrenal cells in culture has been found (Bird et al. 1998). The positive correlation between the APO-CORT and APO$\mathrm{GH}$ responses and the absence of gender and age effects on the APO-CORT responses are also consistent with findings of Mokrani et al. (1995). On the other hand, we were unable to confirm the finding of Mokrani et al. (1995) that the cortisol response to APO was more impaired in paranoid than in disorganized $\mathrm{SCH}$. The lack of significant difference between paranoid and undifferentiated types of $\mathrm{SCH}$ and normal controls in this study appeared to be due to a small sample size, as at least 30 subjects per group are required to produce significant difference between groups, with type I error of 0.05 , power of $80 \%$. Mokrani et al. (1995) found that patients with depression had a normal cortisol response to $\mathrm{APO}$, suggesting some specificity of the blunted cortisol response to APO for SCH and SAD. Since patients with major depression usually have elevated basal cortisol levels (Sachar et al. 1970), it seems unlikely that the blunted cortisol response to APO in the patients with $\mathrm{SCH}$ or SAD are due to the elevated basal cortisol levels noted here. In addition, baseline cortisol levels were covaried in the analysis.

The plasma GH response to APO was significantly blunted in male $\mathrm{SCH}$ patients compared to male normal controls. This blunted GH response was found in neuroleptic-responsive and resistant $\mathrm{SCH}$ as well as in paranoid subtypes of $\mathrm{SCH}$. The degree of blunting in GH secretion in response to APO was somewhat less than that for cortisol. Ettigi et al. (1976), who studied 17 male patients with $\mathrm{SCH}$ compared to 21 male controls, also reported blunted APO-GH responses in patients with $\mathrm{SCH}$, consistent with the result of this study. As in this study, APO-GH response have been consistently reported to be lower in female normal controls and patients with SCH (Lal 1988). No difference in the PRL response to APO between male patients with $\mathrm{SCH}$ and male controls was also consistent with prior reports (Meltzer et al. 1984, Ettigi et al. 1976; Ferrier et al. 1984; Mokrani et al. 1995).

\section{Factors Affecting Hormone Responses to APO}

As APO was well-tolerated, and the study was placebocontrolled, it is unlikely that the blunted cortisol and $\mathrm{GH}$ responses to APO should be attributed to stress. In addition, Brambilla et al. (1997) have reported the blunted APO-GH response in patients with obsessivecompulsive disorder compared to normals, in spite of the stronger emetic response in patients. Thus, stress response to side effects of APO does not appear to be a significant factor influencing hormone responses. Furthermore, the APO-induced PRL response, which is a stress responsive hormone, did not differ between patients with $\mathrm{SCH}$ and control in this and other studies (Meltzer et al. 1984; Ettigi et al. 1976; Ferrier et al. 1984). The APO-CORT response was significantly negatively related to baseline plasma cortisol levels. This suggests that the blunted cortisol response to APO is unlikely to be due to inability to secrete cortisol or to increased clearance of cortisol from plasma. Furthermore, there is evidence that the blunted cortisol response to APO was not due to a ceiling effect or lack of availability of cortisol in the adrenal gland. We have found that the cortisol responses to serotonin (5-HT) agonists, such as 6-chloro-2-(1-piperazinyl)-pyrazine (MK-212) and $\mathrm{m}$-chlorophenylpiperazine (MCPP), are not significantly diminished in patients with $\mathrm{SCH}$ and are significantly greater than those produced by APO (Ranjan et al. 1995; Maes and Meltzer 1996). Neither we nor Mokrani et al. (1995) measured plasma APO levels, so it is possible that pharmacokinetic factors could contribute to the difference in cortisol response to APO. However, the finding that the PRL responses to APO was not significantly different in the patients with SCH compared to normal controls (Meltzer et al. 1984; Ettigi et al. 1976; Ferrier et al. 1984; Mokrani et al. 1995) suggests that availability of APO may not be different between the groups.

The blunted control and GH responses to APO in $\mathrm{SCH}$ are not likely to be due to residual neuroleptic effect, since there was no significant correlation between the duration of drug washout and the cortisol and GH response to APO. Furthermore, baseline plasma PRL levels, which would have been elevated by residual neuroleptic drug, were not significantly different between the patients with $\mathrm{SCH}$ and the normal controls in this study. In addition, the cortisol response to APO was not correlated with age or duration of illness, indi- 
cating that the blunted APO-CORT response was not related to age or chronicity of illness. On the other hand, the APO-GH response was negatively correlated with age and duration of illness in this and our previous study (Meltzer et al. 1984).

Since smoking has been reported to increase plasma cortisol in normals (Kirschbaum et al. 1992) and about $70-80 \%$ of patients with $\mathrm{SCH}$ have been reported to smoke (deLeon 1996), we examined the influence of smoking on the APO-CORT response. We found no effect of smoking status on the APO-CORT response. In addition, subjects were not allowed to smoke from one hour prior to catheter insertion. Similarly, past history of substance abuse did not affect the APO-CORT response.

\section{DA Receptors Mediating Hormone Responses to APO}

Animal studies have suggested that increased activity of the HPA axis can result from either $D_{1}$ or $D_{2}$ receptor stimulation. For example, Borowsky and Kuhn (1992) reported that both the $\mathrm{D}_{1}$ agonist SKF 38393, and the $\mathrm{D}_{2} / \mathrm{D}_{3}$ agonist, quinpirole, stimulate the HPA axis in rats. Furthermore, the $\mathrm{D}_{1}$ antagonist, $\mathrm{SCH} 23390$, and the $\mathrm{D}_{2}$ antagonist, sulpiride, blocked the ACTH and corticosterone increases induced by the corresponding $D_{1}$ and $\mathrm{D}_{2}$ agonists respectively. Fuller and Snoddy (1984) have reported that the $\mathrm{ED}_{50}$ values of $14 \mathrm{DA}$ antagonists for inhibition of the stimulation of corticosterone by pergolide, a DA agonist with a high affinity for $\mathrm{D}_{2}$ and $\mathrm{D}_{3}$ receptors (Sokoloff et al. 1990) and a moderate affinity for $D_{1}$ receptors correlated well with its affinity for the $D_{2}$ receptor, but not with its affinity for the $D_{1}$ receptor. In addition, the pergolide-stimulated corticosterone response was blocked by centrally acting antagonists (e.g. haloperidol and spiperone) but not by a peripherally acting DA antagonist (domperidone) (Fuller and Snoddy 1981). Administration of a $\mathrm{D}_{1}$ or $\mathrm{D}_{2}$ agonist, or the DA uptake inhibitor GBR 12909 into the third ventricle or the paraventricular nucleus of the hypothalamus (but not into the lateral ventricle), stimulated the HPA axis (Borowsky and Kuhn 1992, 1993). In addition, Casolini et al. (1993) have reported that both basal and stressinduced corticosterone secretion is reduced by lesioning the ventral segmental area, the origin of the mesolimbic dopaminergic system. Furthermore, as mentioned earlier, the ventral striatum has been reported to play an important role mediating the corticosterone secretion induced by combined administration of $\mathrm{D}_{1} \mathrm{D}_{2}$ agonists (SKF 38393/quinpirole) in rats (Ikemoto and Goeders 1998). Systemic pretreatment with haloperidol attenuated the elevated corticosterone secretion induced by intra-ventral striatal administration of the two DA agonists (Ikemoto and Goeders 1998). These results suggest that DA stimulates the HPA axis in rodents via stimula- tion of $D_{1}$ or $D_{2}$ receptors, or both, at both the hypothalamic and ventral striatal level. In man, reports are conflicting regarding the role of DA on HPA axis. For example, Jezova and Vigas (1988) and Mokrani et al. (1995) have reported HPA axis stimulation by APO. However, infusion of DA into normal males and females for $5 \mathrm{hrs}$, at two different dose levels, had no effect on plasma ACTH or cortisol (Boesgaard et al. 1990). Similarly, the $\mathrm{D}_{2}$ receptor agonist bromocriptine did not affect ACTH or cortisol level in normal controls (Degli et al. 1979). Furthermore, administration of fenoldopam, a specific $\mathrm{D}_{1}$ agonist, significantly decreased both ACTH and cortisol levels in normal males but not females (Boesgaard et al. 1990). They concluded that there are inhibitory $D_{1}$ receptors at the hypothalamic level.

The APO-stimulated GH responses has been reported to be antagonized by central as well as peripheral $\mathrm{D}_{2}$ antagonists (Lal 1988). On the other hand, neither the $D_{1}$ receptor agonists, SKF 38393 and fenoldopam (Fabbrini et al. 1988; Boesgaard et al. 1990), or the $\mathrm{D}_{1}$ antagonist, NNC 01-0687 (Grodum et al. 1998), affected basal serum GH levels in man. Thus, it is unlikely that $\mathrm{D}_{1}$ receptor stimulation by APO is important to its ability to stimulate $\mathrm{GH}$ secretion.

DA produced by the tuberoinfundibular DA neuron inhibits the release of PRL through an action on the $\mathrm{D}_{2}$ receptor on the pituitary lactotrophs (Ben-Jonathan 1985). Chang and Shin (1999) have reported that DA agonists (DA, apomorphine and bromocriptin) inhibit as well as stimulate PRL release by short form of $D_{2}$ receptors. SCH 23390 pretreatment has been reported to block PRL suppression induced by APO (Apud et al. 1985) and attenuated PRL release by haloperidol (Saller and Salama 1986). Thus, both $D_{1}$ and $D_{2}$ receptors appeared to be involved in PRL suppression induced by DA agonists at the pituitary.

\section{The Dopaminergic Mechanism Mediating the Blunted Cortisol and GH Responses to APO}

The blunted APO-CORT responses in male and female patients with $\mathrm{SCH}$ and the blunted $\mathrm{GH}$ response in male $\mathrm{SCH}$ patients suggests that either the DA receptors mediating these responses are subsensitive to DA or some step in the cascade leading to the release of these hormones is less effective in patients with schizophrenia. Since the APO-stimulated cortisol and GH responses were significantly positively correlated with each other, we hypothesize that the APO-CORT and GH responses share some elements in common, probably mediation by post-synaptic $D_{2}$ DA receptor stimulation. However, $D_{2}$ receptor mechanisms appear to be insufficient to fully explain the APOCORT response. The GH response to APO is completely blocked by chronic treatment with typical antipsychotic drugs, as well as clozapine (Lal 1988; Meltzer 1989). How- 
ever, in a small sample of patients, we have found that chronic treatment with clozapine, which suppresses GH responses to APO, showed a trend to increase the APOCORT response compared to the response in the unmedicated state (Meltzer and Lee, unpublished observation). This is consistent with the studies in rats reporting that a single dose of clozapine stimulated ACTH and corticosterone secretion (Meltzer et al. 1989; Surmann and Havemann-Reinecke 1995) and enhanced the ability of APO to stimulate ACTH and corticosterone secretion in rats (Surmann and Havemann-Reinecke 1995). As mentioned earlier, $\mathrm{D}_{1} \mathrm{DA}$ receptor stimulation appears to be sufficient to stimulate the HPA axis (Borowsky and Kuhn 1992). However, $\mathrm{D}_{1}$ receptors do not appear to be involved in $\mathrm{GH}$ secretion in man (Boesgaard et al. 1990; Fabbrini et al. 1988; Grodum et al. 1998). Thus, the blunted APO-CORT response may be related to functional impairment of $\mathrm{D}_{1}$ or $D_{2}$ receptor mediated events, or both, while the blunted APO-GH response may be related to functional impairment of $\mathrm{D}_{2}$ receptor. Recent neuroimaging studies have reported significantly greater reduction of $\mathrm{D}_{2}$ receptor binding in the striatum after amphetamine challenge in patients with $\mathrm{SCH}$ compared to normals, suggesting enhanced synaptic DA transmission in SCH (Laruelle et al. 1996; Breier et al. 1997). Enhanced synaptic DA transmission could produce functional subsensitivity or down-regulation of post-synaptic DA receptors, which could contribute to the blunted cortisol and GH response to APO.

It is also possible that the APO-GH response may be mediated via peripheral $D_{2}$ receptors as has been reported by Lal (1988) and the APO-CORT response may be mediated via central $D_{2}$ receptor stimulation (Borowsky and Kuhn 1992; Fuller and Snoddy 1981 1984).

The APO-CORT response appears to be independent of serotonergic influences. Treatment with clozapine inhibits cortisol responses stimulated by $5-\mathrm{HT}$ agonists in patient with SCH (Meltzer 1993; Kahn et al. 1993; Curtis et al. 1995), which is in contrast to the enhanced APOCORT responses during clozapine treatment mentioned earlier (Meltzer and Lee, unpublished observation). Furthermore, APO-CORT responses were not correlated with cortisol responses to serotonergic agonists (e.g. L-5-hydroxytryptophan, MK-212, a 5- $\mathrm{HT}_{2 \mathrm{~A}} /{ }_{2 \mathrm{C}}$ agonists, or ipsapirone, a 5- $\mathrm{HT}_{1 \mathrm{~A}}$ agonist) in normal controls (Meltzer and Lee, unpublished observation), which is consistent with a rodent study reported by Fuller and Snoddy (1984). In addition, cortisol response to $5-\mathrm{HT}_{2 \mathrm{~A}} /{ }_{2 \mathrm{C}}$ agonists (MK-212 and MCPP) were not different between patients with SCH and normals (Ranjan et al. 1995; Maes and Meltzer 1996).

\section{The APO-Cortisol Response and Response to Treatment}

The APO-CORT response was not correlated with severity of psychopathology as measured by the BPRS ratings. However, the finding that non-responders to six weeks of antipsychotic drug treatment had significantly lower APO-CORT responses compared to responders suggests that the cortisol response to APO may be related to the central mechanisms which mediate short term improvement in psychopathology in response to typical neuroleptic drugs or clozapine. This contrasts with the lack of relationship between the cortisol response to APO and classification of patients based on their history of treatment responsivity. This suggests that at least some facets of ability of antipsychotic drug treatment to improve psychopathology and the hormone response to APO may reflect actions or related elements of dopaminergic neurotransmission. As mentioned earlier, ventral striatum, which is an anatomical region involved in pathophysiology of $\mathrm{SCH}$ (Lieberman and Koreen 1993), has been reported to be an important region mediating the corticosterone secretion induced by DA agonists in rodents (Ikemoto and Goeders 1998). This may explain why cortisol, but not GH or PRL, responses to APO, predicted treatment response at six weeks. However, it should be noted that Szymanski et al. (1995) previously reported that the APO-induced PRL and GH responses were correlated with response to clozapine at weeks 9 and 12, but not at weeks 3 and 6 .

\section{Nitric Oxide and Apomorphine}

In light of the unusual effects of clozapine on the cortisol response to APO noted above, we considered whether some effect of APO on a non-dopaminergic system might contribute to the striking difference between patients with $\mathrm{SCH}$ and normal controls with regard to its ability increase plasma ACTH and cortisol levels. Nitric oxide (NO) is of interest in this regard since there is considerable evidence that it has an inhibitory effect on corticosterone secretion and that apomorphine enhances NO formation (Melis et al. 1996). NG-nitro-L-arginine methyl ester (L-NAME), an inhibitor of NO synthase, has been reported to increase basal ACTH and corticosterone secretion in rodents (Adams et al. 1992; Giordano et al. 1996). Thus, APO-stimulated NO formation may modulate APO-induced ACTH and cortisol secretion in man. The diminished cortisol response to APO in some patients with $\mathrm{SCH}$ might be related to relatively increased production of NO. NO synthase activity in post-mortem brain specimens has been reported to be higher (Karson et al. 1996) or not different (Doyle and Slater 1995) in cerebellum of patients with SCH compared to normal controls. On the other hand, the density of NO synthase-immunoreactive neurons has been reported to be lower in paraventricular neurons in patients with SCH compared to normal controls (Bernstein et al. 1998). Abnormalities in NO synthesis have been implicated in neurodevelopment and 


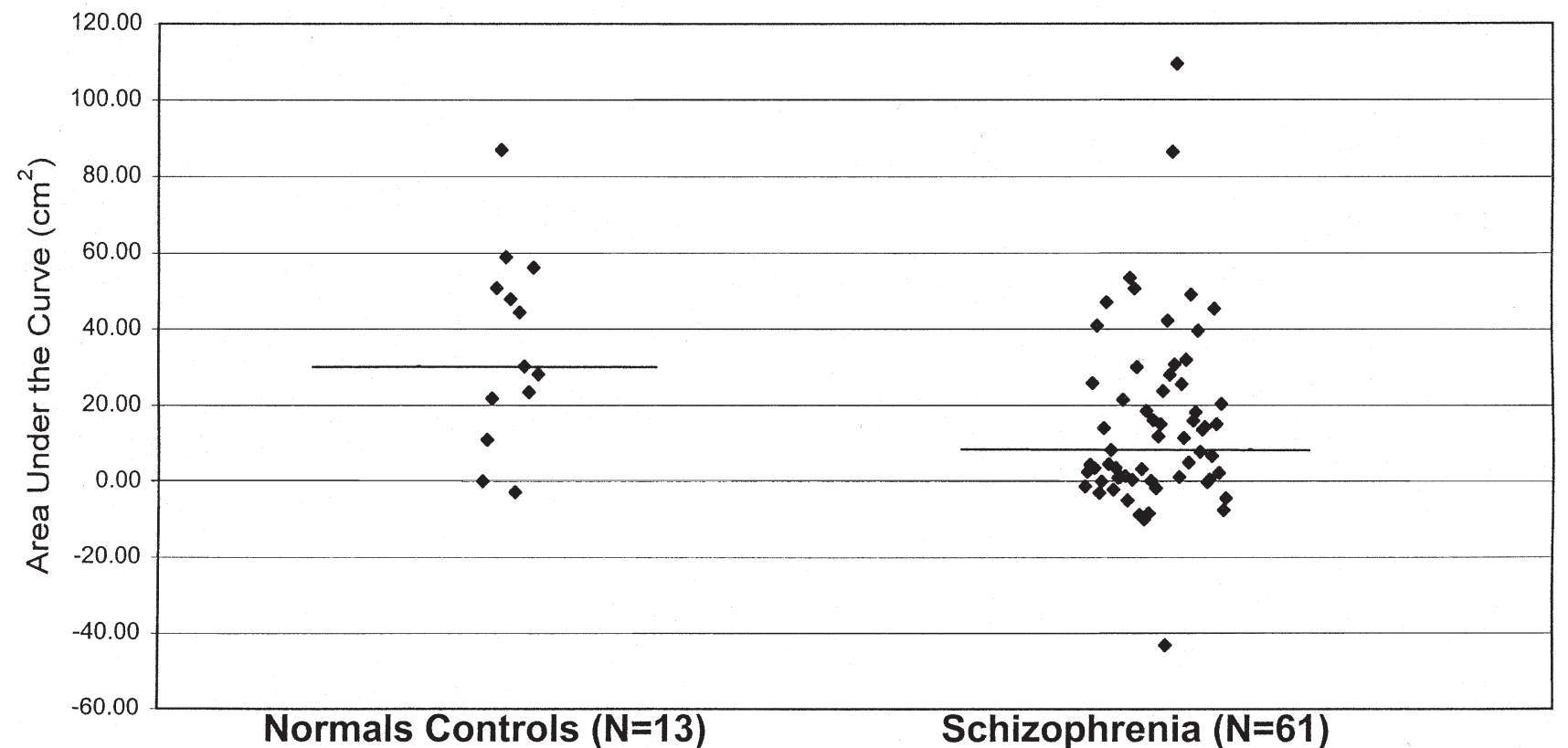

Figure 3. Plasma growth hormone responses to apomorphine in male patients with schizophrenia and male normal controls (a scatter plot using placebo corrected responses). Normal controls vs. schizophrenia: $\mathrm{F}(1,71)=6.24, p=.01$.

increasing the vulnerability to develop SCH (Akbarian et al. 1993; Black et al. 1999). Nitric oxide has been shown to increase the release of DA and influence the activity of the DA transporter in the striatum (Lonart et al. 1993, Kiss et al. 1999). It is possible that excessive NO synthesis might be involved in some more basic aspects of SCH along with contributing to the deficit in cortisol response to APO. The NO synthase inhibitor AR-R17477 has been shown to inhibit the phencyclidine-induced deficit in prepulse inhibition (PPI) and acoustic startle (Johansson et al. 1999). It is possible that the deficit in PPI in patients with SCH may be due to excessive NO production.

\section{Heterogeneity in Responses to Apomorphine in $\mathrm{SCH}$}

There was a marked difference in the cortisol response to APO among the patients with $\mathrm{SCH}$ in that almost half $(25 / 51,49 \%)$ of them had no increase compared to $2 / 15(13 \%)$ of the normal controls. This significantly blunted cortisol responses to APO in patients with $\mathrm{SCH}$ is in contrast to cerebral blood flow responses to APO. For example, APO, at a dose comparable to that used in this study, activated blood flow to the anterior cingulate cortex and the prefrontal cortex, bilaterally, while it deactivated blood flow to the left superior temporal gyrus, during a verbal fluency (semantic memory) task in 12 unmedicated patients with $\mathrm{SCH}$ to a greater extent than in normal controls, indicating an enhanced response to APO in the patient group (Grasby et al. 1992; Fletcher et al. 1996). APO also improved verbal fluency performance in the patients whereas it had no effect in the controls (Fletcher et al. 1996). They suggested that this enhanced response to APO in SCH might be mediated via a pre-synaptic DA mechanism (Fletcher et al 1996). Thus, the heterogeneous responses to APO (the blunted cortisol, but enhanced cerebral blood flow responses to $\mathrm{APO}$ ) in $\mathrm{SCH}$ may be, in part, related to post- versus pre-synaptic DA receptor responsivity or regional difference in DA receptor responsivity. Further studies are needed to understand the biological basis for this heterogeneous responses to APO in SCH.

In summary, the APO-stimulated cortisol and GH responses were blunted in patients with $\mathrm{SCH}$ compared to normal controls. The cortisol response of the patients with $\mathrm{SCH}$ to APO appears to be bimodal with a large proportion of patients showing no increase at all. The blunted APO-stimulated cortisol responses may be due to $\mathrm{D}_{2}$ or $\mathrm{D}_{1}$, or both, receptor dysfunction while the blunted APO-stimulated GH responses may reflect abnormal $\mathrm{D}_{2}$ receptor mediated responses. In addition, the blunted APO-stimulated cortisol responses were found to predict poor therapeutic response to antipsychotic drug treatment. These results suggest further study of the HPA axis response to APO as a predictor of treatment response and an index of central dopaminergic function is warranted.

\section{REFERENCES}

Adams ML, Nock B, Truong R, Cicero TJ (1992): Nitric oxide control of steroidogenesis: endocrine effects of NG- 
nitro-L-arginine and comparisons to alcohol. Life Sci 50:PL35-40

Akbarian S, Bunney WE, Potkin SG, Wigal SB, Hagman JO, Sandman CA, Jones EG (1993): Altered Distribution of Nicotinamide-Adenine Dinucleotide Phosphate-Diaphorase Cells in Frontal Lobe of Schizophrenics Implies Disturbances of Cortical Development. Arch Gen Psychiatry 50:169-177

American Psychiatric Association (1987): Diagnostic and Statistical Manual of Mental Disorders, 3rd editionrevised (DSM-III-R). Washington, DC, American Psychiatric Press

Apud JA, Masotto C, Ongini E, Racagni G (1985): Interaction of SCH 23390, a D-1-selective antagonist, with the anterior pituitary D-2 receptors and prolactin secretion in the rat. Eur J Pharmacol 112:187-193

Ben-Jonathan N (1985): Dopamine: a prolactin-inhibiting hormone. Endocrine Rev 6:564-589

Bernstein HG, Stanarius A, Baumann B, Henning H, Krell D, Danos P, Falkai P, Bogerts B (1998): Nitric oxide synthase-containing neurons in the human hypothalamus: reduced number of immunoreactive cells in the paraventricular nucleus of depressive patients and schizophrenics. Neuroscience 83:867-875

Bird IM, Lightly ERT, Nicol M, Williams BC, Walker SW (1998): Dopaminergic stimulation of cortisol secretion from bovine ZFR cells occurs through nonspecific stimulation of adrenergic p-receptors. Endocrin Res 74:769-772

Black MD, Selk DE, Hitchcock JM, Wettstein JG, Sorensen SM (1999): On the effect of neonatal nitric oxide synthase inhibition in rats: a potential neurodevelopmental model of schizophrenia. Neuropharmacology 38:1299-1306

Boesgaard S, Hagen C, Andersen AN, Fenger M, Eldrup E (1990): Effect of dopamine, dopamine D-1 and D-2 receptor modulation on ACTH and cortisol levels in normal men and women. Acta Endocrinol (Copenh)122: 29-36

Borowsky B, Kuhn, CM (1992): $\mathrm{D}_{1}$ and $\mathrm{D}_{2}$ dopamine receptors stimulate hypothalamo-pituitary-adrenal activity in rats. Neuropharmacology 31:671-678

Borowsky B, Kuhn, CM (1993): GBR 12909 stimulates hypothalamo-pituitary-adrenal activity by inhibition of uptake at hypothalamic dopamine neurons. Brain Res 613:251-258

Brambilla F, Bellodi L, Perna G, Arancio C, Bertani A (1997): Dopamine function in obsessive-compulsive disorder: growth hormone response to apomorphine stimulation. Biol Psychiatry 42:889-897

Breier A, Su T-P, Saunders R, Carson RE, Kolachana BS, de Bartolomeis A, Eckelman WC, Pickar D (1997): Schizophrenia is associated with elevated amphetamineinduced synaptic dopamine concentrations: evidence from a novel positron emission tomography method. Proc Natl Acad Sci USA 94:2569-2574

Brown G, Cleghorn J, Kaplan R, Szechtman H, Brown P, Szechtman B, Mitton J (1988): Longitudinal growth hormone studies in schizophrenia. Psychiatry Research 24:123-136

Carey RJ, Pinheiro-Carrera M, Dai H, Tomaz C and Huston JP (1995): L-DOPA and psychosis: evidence for L-DOPAinduced increase in prefrontal cortex dopamine and in serum corticosterone. Biol. Psychiatry 28:669-676
Casolini P, Kabba JM, Piazza PV, Rouge-Pont F, Angelucci L, Simon H, Le Moad M, Maccari S, (1993): Basal and stress-induced corticosterone secretion is decreased by lesion of mesencephalic dopaminergic neurons. Brain Res 622:311-314

Chang A, Shin SH (1999): Dopamine agonists both stimulate and inhibit prolactin release in GH42R7 cells. Eur J Endocrinol 141:387-395

Cleghorn JM, Brown GM, Brown PJ, Kaplan RD, Mitton J (1983): Longitudinal instability of hormone responses in schizophrenia. Prog Neuropsychopharmacol Biol Psychiatry 7:545-549

Creese I (1987): Biochemical properties of CNS dopamine receptors. In Meltzer HY (ed), Psychopharmacology: The Third Generation of Progress. Raven Press, New York, pp 257-264

Curtis VA, Wright P, Reveley A, Kerwin R, Luce JV (1995): Effect of clozapine on d-fenfluramine-evoked neuroendocrine responses in schizophrenia and its relationship to clinical improvement. Br J Psychiatry 166:642-646

Degli U EC, Fabbri BL, Margutti, AR, Fersini CM, Pansini R, (1979) Effect of bromocriptine on the control of aldosterone diurnal variations in normal supine man. Horm Res 1979: 10:64-78

deLeon J (1996): Smoking and vulnerability for schizophrenia. Schizophrenia Bull 22:405-409

Doyle CA, Slater P (1995): Application of [3H]L-N(G)-nitroarginine labelling to measure cerebellar nitric oxide synthease in patients with schizophrenia. Neurosci Lett 202:49-52

Endicott J, Spitzer RL (1978): A diagnostic interview: The schedule for affective disorders and schizophrenia. Arch. Gen. Psychiatry 35:837-844

Ettigi P, Nair NPV, Lal S, Cervantes P, Guyda H (1976): Effect of apomorphine on growth hormone and prolactin secretion in schizophrenic patients, with or without oral dyskinesia, withdrawn from chronic neuroleptic therapy. J Neurol Neurosurg Psychiatry 39:870-876

Fabbrini G, Braun A, Mouradian MM, Tamminga CA, Chase TN (1988): Dopamine D-1 receptor agonist stimulation of prolactin secretion in man. J Neural Transm 71:159-163

Ferrier IN, Johnstone EC, Crow, TJ (1984): Clinical effects of apomorphine in schizophrenia. Brit J Psychiatry 144: 341-348

Fletcher PC, Frith CD, Grasby PM, Friston KJ, Dolan, RJ (1996): Local and distributed effects of apomorphine on fronto-temporal function in acute unmedicated schizophrenia. J Neuroscience 16: 7055-7062

Fuller RW, Snoddy HD (1984): Central dopamine receptors mediating pergolide-induced elevation of serum corticosterone in rats. Neuropharmacology 23:1389-1394

Fuller RW, Snoddy HD (1981): Elevation of serum corticosterone concentration in rats by pergolide and other dopamine agonists. Endocrinology 105: 1026-1032

Giordano M, Vermeulen M, Trevani AS, Dran G, Andonegui G, Geffner JR (1996): Nitric oxide synthase inhibitors enhance plasma levels of corticosterone and ACTH. Acta Physiologica Scandinavica 157:259-264

Grasby, PM, Fristorn KJ, Gench CJ, Firth CD, Paulesu E, Coen PJ, Liddle PF, Frackowiak RSH, Rolan RJ (1992): The effect of apomorphine and buspirone on regional 
cerebral blood flow during the performance of a cognitive task: measuring neuromodulatory effects of psychotropic drugs in man. Eur J Neurosc 4: 1203-1212

Grodum E, Andersen M, Hangaard J, Koldkjaer O, Hagen C (1998): lack of effect of the dopamine $D_{1}$ antagonist, NNC 01-0687, on unstimulated and stimulated release of anterior pituitary hormones in males. J Endocrinol Invest 21:291-297

Ikemoto S, Goeders NE (1998): Microinjections of dopamine agonists and cocaine elevate plasma corticosterone: dissociation effects among the ventral and dorsal striatum and medial prefrontal cortex. Brain Res 814:171-178

Jezova D, Vigas M (1988): Apomorphine injection stimulates p-endorphin, adrenocorticotropin and cortisol release in healthy man. Psychoneuroendocrinology 13:479-485

Johansson C, Daveney AM, Reif D, Jackson DM (1999): The neuronal selective nitric oxide inhibitor AR-R 17477 blocks effects of phencyclidine, while having no observable behavioural effects when given alone. Pharmacol \& Toxicol 84:226-233

Kahn RS, Siever L, Davidson M, Greenwald C, Moore C (1993): haloperidol and clozapine treatment and their effect on $\mathrm{m}$-chlorophenylpiperazine-mediated responses in schizophrenia: implications for the mechanism of action of clozapine. Psychopharmacol 112:S90-S94

Kane J, Honigfield G, Singer J, Meltzer HY, the Clozaril Collaborative Study Group (1988): Clozapine for the treatment-resistant schizophrenia: A double-blind comparison with chlorpromazine/benztropine. Arch Gen Psychiatry 45:789-796

Karson CN, Griffin WS, Mrak RE, Husain M, Dawson TM, Snyder SH, Moore NC, Sturner WQ (1996): Nitric oxide synthase (NOS) in schizophrenia: increases in cerebellar vermis. Mol Chem Neuropathol 27:275-284

Kirschbaum C, Wust S, Strasburger CJ (1992): 'Normal' cigarette smoking increases free cortisol in habitual smokers. Life Sci 50:435-442

Kiss JP, Hennings EC, Zsilla G, Vizi ES (1999): A possible role of nitric oxide in the regulation of dopamine transporter function in the striatum. Neurochem Int 34:345-350

Lal, S (1988): Apomorphine in the evaluation of dopaminergic function in man. Prog Neuropsychopharmacol \& Biol Psychiatry 12:117-164

Laruelle M, Abi-Dargham A, van Dyck CH, Gil R, D'Souza CD, Erdos J, McCance E, Rosenblatt W, Fingado C, Zoghbi SS, Baldwin RM, Seibyl JP, Krystal JH, Charney DS, Innis RB (1996): Single photon emission computerized tomography imaging of amphetamine-induced dopamine release in drug-free schizophrenic subjects. Proc Natl Acad Sci USA 93:9235-9240

Lieberman JA, Koreen AR (1993): Neurochemistry and neuroendocrinology of schizophrenia: A selective review. Schizophrenia Bulletin 19:371-429

Lonart G, Cassels KL, Johnson KM (1993): Nitric oxide induces calcium-dependent $[3 \mathrm{H}]$ dopamine release from striatal slices. J Neurosci Res 35:192-198

Maes M, Meltzer HY (1996): Effects of meta-chlorophenylpiperazine on neuroendocrine and behavioral responses in male schizophrenic patients and normal volunteers. Psychiatry Res 64:147-159

Mansbach RS, Brooks EW, Sanner MA, Zorn SH (1998):
Selective dopamine $\mathrm{D}_{4}$ receptor antagonists reverse apomorphine-induced blockade of prepulse inhibition. Psychopharmacology 135:194-200

Melis MR, Succu S, Argiolas A (1996): Dopamine agonists increase nitric oxide production in the paraventricular nucleus of the hypothalamus: correlation with penile erection and yawning. Eur J Neurosci 8:2056-2063

Meltzer HY (1989): Clinical studies on the mechanism of action of clozapine: the dopamineserotonin hypothesis of schizophrenia. Psychopharmacology 99: S18-27

Meltzer HY (1993): Serotonin-dopamine interactions and atypical antipsychotic drugs. Psychiatr Ann 23: 193-200

Meltzer HY (1995): Dopamine, serotonin and glucocorticoids and the psychopathology of schizophrenia. In Fog R, Gerlach J, Hemmingsen R (eds), Schizophrenia. Afred Benzon symposium 38. Munksgaard, Copenhagen, pp 74-91

Meltzer HY, Koenig JL, Nash JF, Gudelsky GA (1989): Melperone and clozapine: neuroendocrine effects of atypical neuroleptic drugs. Acta Psychiatr Scandinavia (suppl) 352:24-29

Meltzer HY, Kolakowska T, Fang VS, Fogg L, Robertson A, Lewine R, Strahilevitz M, Busch D (1984): Growth hormone and prolactin response to apomorphine in schizophrenia and the major affective disorders. Arch Gen. Psychiatry 41:512-519

Monteleone P, Tortorella A, Borriello R, Cassandro P, Maj M (1999): Prolactin hyperresponsiveness to d-fenfluramine in drug-free schizophrenic patients: a placebo-controlled study. Biol Psychiatry 45:1606-1611

Mokrani MC, Duval F, Crocq MA, Bailey PE, Macher JP (1995): Multihormonal responses to apomorphine in mental illness. Psychoneuroendocrinology 20:365-375

Muller-Spahn F, Modell SS, Ackenheil M, Brachner A, Kurtz $G$ (1998): Elevated response of growth hormone to graded doses of apomorphine in schizophrenic patients. J Psychiatric Research 32:265-271

Overall JE, Gorham DR (1962): The Brief Psychiatric Rating Scale. Psychological Res 10:799-812

Ranjan R, Lee MA, Meltzer HY (1995): Effect of MK-212, a centrally acting serotonin agonist, on prolactin, cortisol and body temperature in schizophrenia. Biol Psychiatry 37:678-679

Sachar EJ, Hellman L, Fukushima DK, Gallagher TF (1970): Cortisol production in depressive illness: A clinical and biochemical clarification. Archives of General Psychiatry 23:289-298

Saller CF, Salama AI (1986): D-1 and D-2 dopamine receptor blockade: interactive effects in vitro and in vivo. J Pharmacol Exp Ther 236:714-720

Seeman P, Van Tol HHM (1990): Dopamine $\mathrm{D}_{4}$ receptors bind inactive $(+)$ aporphines suggesting neuroleptic role. Sulpiride not stereoselective. Eur J Pharmacol 233:173-174

Sokoloff P, Giros B, Mortres MP, Bouthenet ML, Schwartz JC (1990): Molecular cloning and characterization of a novel dopamine receptor $\left(\mathrm{D}_{3}\right)$ as a target for neuroleptics. Nature 347:146-151

Surmann A, Havemann-Reinecke U (1995): Injection of apomorphine - a test to predict individual different dopaminergic sensitivity? J Neurol Transm (Suppl) 45:143-155 
Szymanski S, Lieberman J, Pollack S, Safferman A, Munne R, Umbrich D, Kane J, Kronig M, Chakos M, Cooper T (1995): Clozapine effects on neuroendocrine response to apomorphine challenge testing in chronic neuroleptic nonresponsive schizophrenia; preliminary finding. Biological Psychiatry 37:51-55

Tamminga CA, Smith RC, Pandey G, Frohman LA, Davis
JM (1977): A neuroendocrine study of supersensitivity in tardive dyskinesia. Arch Gen Psychiatry 36:11991203

Zemlan FP, Hirschowitz J, Garver DL (1986): Relation of clinical symptoms to apomorphine-stimulated growth hormone release in mood-incongruent psychotic patients. Arch. Gen. Psychiatry; 43:1162-1167 